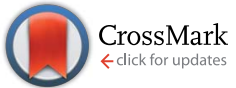

Cite this: RSC Adv., 2015, 5, 101607

Received 9th October 2015

Accepted 10th November 2015

DOI: $10.1039 / \mathrm{c} 5 \mathrm{ra} 20927 \mathrm{~g}$

www.rsc.org/advances

\title{
Triisopropylsilylacetylene-functionalised anthracene-alt-benzothiadiazole copolymers for application in bulk heterojunction solar cells $\uparrow$
}

\author{
Luke Cartwright, ${ }^{a}$ Lois. J. Taylor, ${ }^{a}$ Hunan Yi, ${ }^{a}$ Ahmed Iraqi, ${ }^{\star a}$ Yiwei Zhang, ${ }^{b}$ \\ Nicholas. W. Scarratt, ${ }^{b}$ Tao Wang ${ }^{c}$ and David. G. Lidzey*b
}

Three triisopropylsilylacetylene-functionalised anthracene (TIPSAnt) based polymers were synthesised by copolymerising TIPSAnt with either dithienyl-5,6-difluoro-benzo[c]-[1,2,5]thiadiazole, dithienyl-benzo[c]$[1,2,5]$ thiadiazole or dibithiophenyl-benzo[c]-[1,2,5]thiadiazole to yield PTATffBT, PTATBT- 8 and PTAT2BT-8, respectively. PTAT2BT-8 demonstrated a reduced optical and electrochemical band gap, relative to PTATffBT and PTATBT-8. The HOMO level of PTAT2BT-8 $(-5.32 \mathrm{eV})$ is significantly shallower compared to its counterparts. This can be attributed to increased intramolecular charge transfer along the polymer backbone; a consequence of the incorporation of additional thiophene spacer units. The photovoltaic properties of the polymers were investigated by fabricating bulk heterojunction (BHJ) polymer solar cells using $\mathrm{PC}_{70} \mathrm{BM}$ as the electron acceptor. PTATffBT displayed limited solubility in common organic solvents and could not be used for the fabrication of photovoltaic cells. Optimised photovoltaic devices fabricated from PTATBT-8 and PTAT2BT-8 demonstrated power conversion efficiencies of $2.36 \%$ and $3.15 \%$, respectively. PTAT2BT- 8 provided better efficiencies chiefly as a result of better $J_{\mathrm{sc}}$ and $\mathrm{FF}$ values.

\section{Introduction}

The combustion of fossil fuels releases carbon dioxide; a gas that accentuates the greenhouse effect and climate change. This has prompted the scientific community to develop new forms of renewable energy. Polymer solar cells (PSC) have the potential to provide a clean source of energy owing to their ease of fabrication and low production costs. ${ }^{\mathbf{1 , 2}}$

The most successful PSCs to date are devices fabricated using a bulk heterojunction (BHJ) active layer architecture. ${ }^{3-6}$ An n-type material, commonly a fullerene derivative, is blended with a conjugated polymer, $\mathrm{p}$-type material to form a nanoscale, bicontinuous interpenetrating network. ${ }^{7}$ Fullerene derivatives find wide-scale application as near ideal n-type materials for PSCs. ${ }^{8-10}$ However, the development of new donor-acceptor (DA) alternating conjugated copolymers is essential if the efficiencies of PSCs are to rival inorganic devices. ${ }^{11}$ It is important that the conjugated polymer has a low optical band gap, high

\footnotetext{
${ }^{a}$ Department of Chemistry, University of Sheffield, Sheffield, S3 7HF, UK. E-mail: a. iraqi@Sheffield.ac.uk; Fax: +44 (0)114 222 9303; Tel: +44 (0)114 2229566

${ }^{b}$ Department of Physics and Astronomy, University of Sheffield, S3 7RH, UK. E-mail: $d$. g.lidzey@sheffield.ac.uk; Fax: +44 (0)114 222 3555; Tel: +44 (0)114 2223501

${ }^{c}$ School of Materials Science and Engineering, Wuhan University of Technology, Wuhan 430070, China

$\dagger$ Electronic supplementary information (ESI) available: ${ }^{1} \mathrm{H},{ }^{13} \mathrm{C}$ of M1. ${ }^{1} \mathrm{H}$ NMR spectra of the polymers. See DOI: $10.1039 / \mathrm{c} 5 \mathrm{ra20927g}$
}

absorption coefficients, finely tuned frontier energy levels and high hole mobilities. ${ }^{12}$ Such conjugated polymers must ideally have excellent solubility in common organic solvents to ensure the photovoltaic device can be fabricated using low-cost solution based processing. ${ }^{\mathbf{1 3 , 1 4}}$

Kallmann and Pope were the first to investigate the photovoltaic effect in organic anthracene crystals. ${ }^{15}$ Since then, the body of work covering anthracene and its optoelectronic properties has been extended. Anthracene and the acene family in general, possess extended $\pi$-conjugated systems resulting in planar molecules with a high degree of crystallinity. ${ }^{16} \pi$-conjugated systems aid electron transfer along the polymer backbone resulting in high charge mobility. Furthermore, anthracene is an extremely versatile molecule and can be polymerised through its 2,6-positions or 9,10-positions. ${ }^{17-22}$ Providing that the polymerisation is conducted through the 2,6-positions, the 9,10-positions can be functionalised with substituents; affording a way to tune the optoelectronic properties of the resulting polymer. ${ }^{19}$ Consequently, anthracene and its derivatives have found widespread use in organic-field effect transistors and organic light emitting diodes. ${ }^{23-27}$

The use of anthracene in PSC is limited, which is surprising considering that benzo[1,2- $\left.b: 4,5-b^{\prime}\right]$ dithiophene (BDT), which has an analogous molecular framework, has found widespread use in high performance PSC devices. ${ }^{28-32}$ Park et al. reported a new class of anthracene-thiophene based copolymers incorporating bulky triisopropylsilylacetylene (TIPS) groups at the 
9,10-positions of the anthracene moiety. ${ }^{32}$ It was reported that the incorporation of TIPS groups overcame the poor charge transportation properties and high crystallinity that are generally associated with polythiophene-based copolymers. The polymer yielded efficiencies of $1.70 \%$ when blended with $\mathrm{PC}_{60} \mathrm{BM}$ and used as the active layer in a $\mathrm{BHJ}$ photovoltaic device. $^{32}$ Iraqi and co-workers presented the preparation of donor-acceptor polymers with alternating 2,6-linked anthracene units with aryloxy substituents at their 9,10-positions and various benzothiadiazole alternate repeat units. Efficiencies ranging from 1.93 to $4.17 \%$ were measured for these polymers. ${ }^{33}$ More recently, Jo and co-workers synthesised a copolymer composed of thienyl substituted anthracene and diketopyrrolopyrrole. The resulting polymer exhibited an efficiency of $7.02 \%$ and $4.23 \%$ when blended with $\mathrm{PC}_{70} \mathrm{BM}$ and di-perylene bisimide, respectively. ${ }^{18}$

Here, we report the synthesis and optoelectronic properties of three anthracene-alt-benzothiadiazole donor-acceptor copolymers, PTATffBT, PTATBT-8 and PTAT2BT-8. The study focusses on incorporating TIPS groups at the 9,10-positions of the anthracene unit and the impact of various benzothiadiazole acceptors. PTATffBT was highly insoluble and photovoltaic devices could not be fabricated from this polymer. Organic photovoltaic devices based on PTATBT-8 and PTAT2BT-8 display power conversion efficiencies (PCEs) of $2.36 \%$ and $3.15 \%$, respectively, when blended with $\mathrm{PC}_{70} \mathrm{BM}$ in $\mathrm{BHJ}$ photovoltaic devices.

\section{Results and discussion}

\section{Monomer and polymer synthesis}

The preparation of monomers and polymers are outlined in Scheme 1. Anthracene dibromide (3) was prepared according to literature procedures. ${ }^{34}$ It was then converted to the bis-boronate ester (M1) upon reaction with bis(pinacolato)diboron in the presence of $\mathrm{Pd}(\mathrm{dppf}) \mathrm{Cl}_{2}$.

M1 was then reacted with $\mathbf{M 2}, \mathbf{M} 3$ and M4, via Suzuki coupling, in the presence of $\mathrm{Pd}(\mathrm{OAc})_{2}$ and tri(o-tolyl)phosphine, to yield PTATfB', PTATBT-8 and PTAT2BT-8, respectively. The polymers were fractionated via Soxhlet extraction using the solvents; methanol, acetone, hexane and toluene. All polymers were obtained as deep purple powders. The yield of PTAT2BT-8 was significantly lower than PTATffBT and PTATBT-8 and large amounts of insoluble polymer remained in the thimble after Soxhlet extraction. This suggests that the incorporation of additional thiophene units together with the small solubilising TIPS substituents positioned on the anthracene unit were not able to facilitate the processability of the high molecular mass fraction of the polymer. Despite large quantities of PTATffBT being extracted in the toluene fraction, it should be noted that PTATffBT exhibited poor solubility in common organic solvents such as chloroform, chlorobenzene, $o$-dichlorobenzene and 1,2,4-trichlorobenzene at elevated temperatures. Consequently, photovoltaic devices could not be fabricated from PTATffBT. The chemical structures of PTATffBT, PTATBT-8 and PTAT2BT-8 were confirmed via ${ }^{1} \mathrm{H}-\mathrm{NMR}$ and elemental analysis. The number average molecular weight $\left(M_{\mathrm{n}}\right)$ and weight average

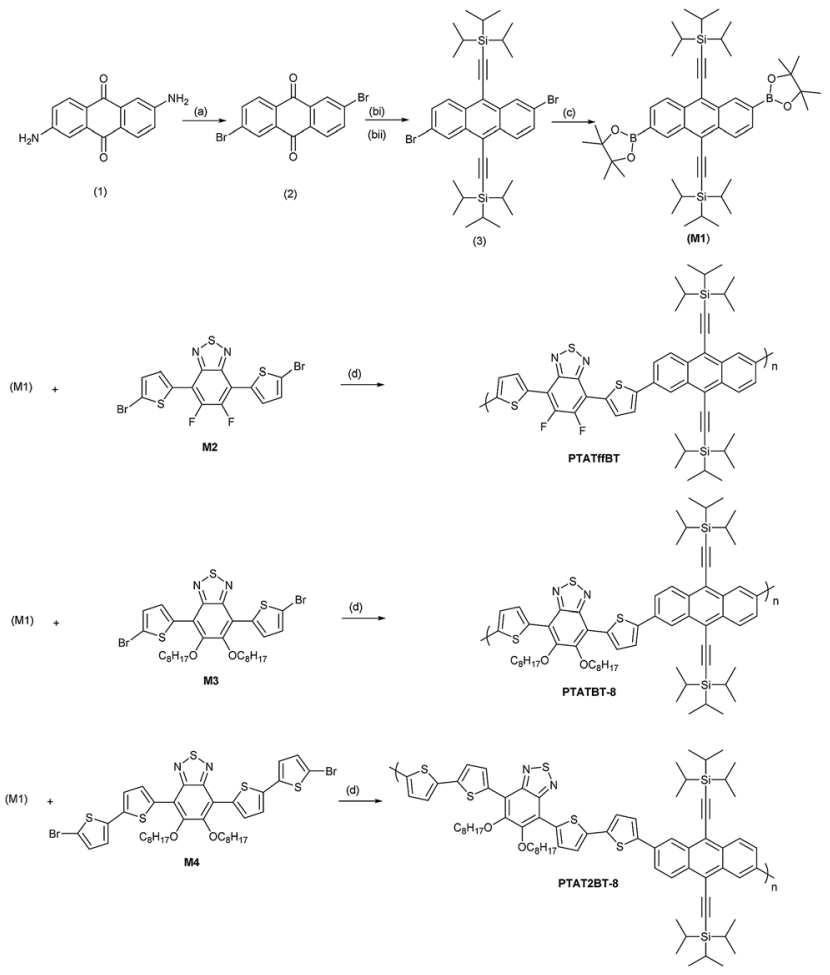

Scheme 1 Synthesis of 2,6-bis-4,4,5,5-tetramethyl-1,3,2-dioxaborolan-2-yl)-9,10-bis(triisopropylsilylacetylene) anthracene (4): (a) $\mathrm{CuBr}_{2}, t$-BuONO, $\mathrm{CH}_{3} \mathrm{CN}$; (bi) $n$-BuLi, TIPS, THF, 24 hours; (bii) $\mathrm{SnCl}_{2}$, $\mathrm{HCl}\left(10 \%\right.$ aq.); (c) bis(pinacolato)diboron, KOAc, $\mathrm{Pd}(\mathrm{dppf}) \mathrm{Cl}_{2}, \mathrm{DMF}$; (d) $\mathrm{Pd}(\mathrm{OAc})_{2}, \mathrm{P}(\mathrm{o}-\text { tolyl })_{3}, \mathrm{NEt}_{4} \mathrm{OH}$, toluene.

molecular weight $\left(M_{\mathrm{w}}\right)$ of all polymers were measured using high-temperature $\left(140{ }^{\circ} \mathrm{C}\right)$ gel permeation chromatography (GPC) using 1,2,4-trichlorobenzene as the eluent and polystyrene as the internal standard (Table 1). PTATBT-8 displayed a $M_{\mathrm{n}}$ of 13600 and a $M_{\mathrm{w}}$ of 38700 Da. PTAT2BT-8 displayed a reduced $M_{\mathrm{n}}(6600 \mathrm{Da})$ and a $M_{\mathrm{w}}(13200 \mathrm{Da})$ relative to PTATBT-8, which can be attributed to the incorporation of additional thiophene-spacer units without solubilising groups. PTATffBT displayed significantly reduced $M_{\mathrm{n}}$ and $M_{\mathrm{w}}$ values of $2100 \mathrm{Da}$ and $2500 \mathrm{Da}$, respectively as a result of the absence of solubilising substituents on the TffBT units. Furthermore, previous studies have also indicated that incorporation of fluorine on the benzothiadiazole-moiety facilitates stronger $\pi-\pi$ stacking and aggregation of polymer chains, which severely limits accessibility to high molecular weight materials. ${ }^{35,36}$

\section{Optical properties}

The absorption spectra of the polymers were recorded both in solution (chloroform) and as drop-cast films (Fig. 1). The optical band gap and absorption value maxima are shown in Table 1. PTATffBT displays absorptions maxima at 357, 455 and $520 \mathrm{~nm}$ in chloroform solution and at 328, 469 and $523 \mathrm{~nm}$ in films. The lack of a significant bathochromic shift from solution to film indicates that the polymers adopt similar energetic conformations in both solution and film states. The additional peaks in the UV-vis spectra of PTATffBT are attributed to the 
Table 1 GPC data, UV-vis data, energy levels and energy gaps of the polymers

\begin{tabular}{|c|c|c|c|c|c|c|c|c|}
\hline Polymer & $M_{\mathrm{n}}^{a}(\mathrm{Da})$ & $M_{\mathrm{w}}{ }^{a}(\mathrm{Da})$ & $\lambda_{\max }$ solution $(\mathrm{nm})$ & $\lambda_{\max }$ film $(\mathrm{nm})$ & $E_{\mathrm{g}}^{\mathrm{opt} b}(\mathrm{eV})$ & $\operatorname{HOMO}^{c}(\mathrm{eV})$ & $\operatorname{LUMO}^{d}(\mathrm{eV})$ & $E_{\mathrm{g}}^{\text {elece }}(\mathrm{eV})$ \\
\hline PTATffBT & 2100 & 2500 & $357,455,520$ & $328,469,523$ & 1.92 & -5.48 & -3.16 & 2.32 \\
\hline PTATBT-8 & 13600 & 38700 & 344,524 & 369,555 & 1.85 & -5.46 & -3.42 & 2.04 \\
\hline
\end{tabular}

${ }^{a}$ Measurements conducted on the toluene fractions of polymers using a differential refractive index (DRI) detection method. ${ }^{b}$ Optical energy gap determined from the onset of the absorption band in thin film. ${ }^{c}$ HOMO position (vs. vacuum) determined from the onset of oxidation. ${ }^{d}$ LUMO position (vs. vacuum) determined from the onset of reduction. ${ }^{e}$ Electrochemical energy gap.
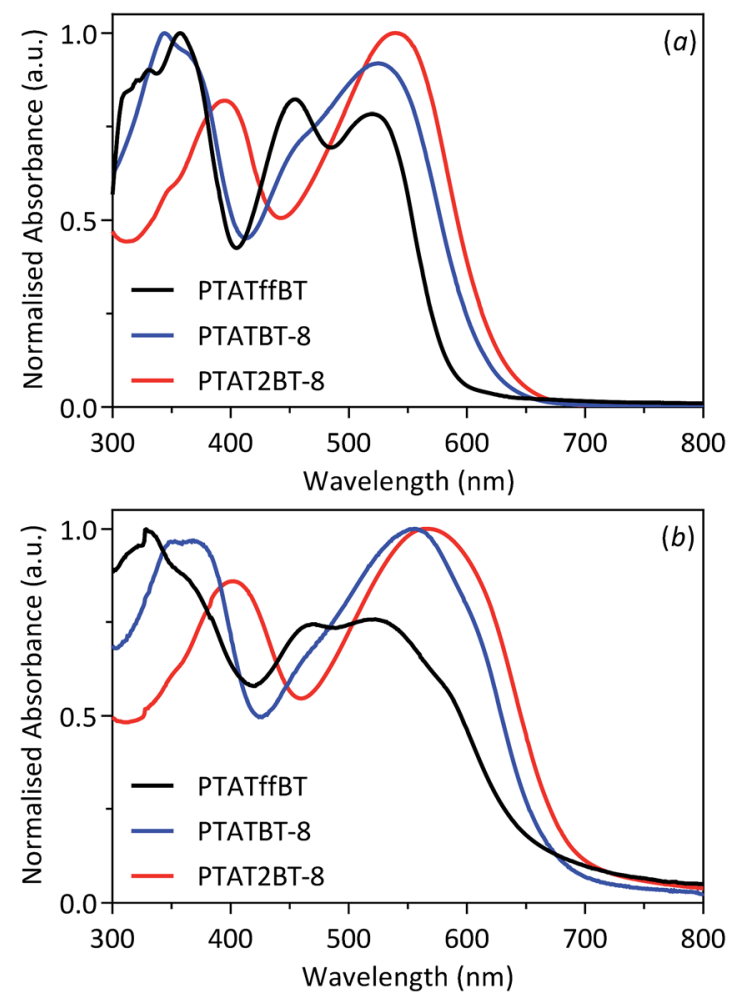

Fig. 1 Normalised absorption spectra of PTATffBT, PTATBT-8 and PTAT2BT-8 in: (a) chloroform solutions; and (b) thin films.

inhomogeneously-broadened electronic and vibrational transitions of the polymer. The optical band gap of PTATffBT was calculated to be $1.92 \mathrm{eV}$. The large optical band gap can be attributed to the low molecular weight of PTATffBT.

PTATBT-8 displays absorption bands in the visible region at 524 and $556 \mathrm{~nm}$, in chloroform solution and film states, respectively. The bathochromic shift that is observed from solution to film can be ascribed to a more coplanar structure in solid state. PTAT2BT-8 displays a maximum at $540 \mathrm{~nm}$ in chloroform solution. The absorption maximum of PTAT2BT-8 is red-shifted to $566 \mathrm{~nm}$ when cast into a thin-film. The intramolecular charge transfer (ICT) band in the solid-state optical spectrum of PTAT2BT-8 is more pronounced relative to the $\pi-\pi^{*}$ band. This phenomenon is not evident in PTATBT-8. Furthermore, the optical band gap of PTAT2BT-8 $(1.81 \mathrm{eV})$ is lower than that of PTATBT-8 $(1.85 \mathrm{eV})$. We speculate that the incorporation of a bithiophene spacer-unit facilitates intramolecular charge transfer along the polymer backbone resulting in increased electronic delocalisation and a reduced optical band gap. The optical band gaps of PTATBT-8 and PTAT2BT-8 are located close to the maximum solar flux.

PTATBT-8 and PTAT2BT-8 are analogous to two polymers previously synthesised by Iraqi and co-workers (PPATBT-8 and PPAT2BT-8). ${ }^{33}$ In PPATBT-8 and PPAT2BT-8 the anthracene moiety is functionalised with 4-dodecyloxybenzene groups, instead of TIPS. PPATBT-8 and PPAT2BT-8 have optical band gaps of 1.96 and $1.86 \mathrm{eV}$, respectively. ${ }^{33}$ We speculate that the acetylene group and the long $\mathrm{C}-\mathrm{Si}$ bond present in TIPS locate the solubilising alkyl chains further away from the conjugated backbone, which facilitates planarization of the polymer backbone and improves $\pi-\pi$ interchain stacking. This result is consistent with the reduced $M_{\mathrm{n}}$ and $M_{\mathrm{w}}$ values obtained for PTATBT-8 and PTAT2BT-8, relative to PPATBT-8 and PPAT2BT-8.

\section{Electrochemical properties}

The frontier energy levels ( $v s$. vacuum) of the polymers were determined from the onsets of oxidation and reduction (Table 1). The onsets were determined via cyclic voltammetry measurements, which were conducted on drop-cast polymer films in acetonitrile with tetrabutylammonium perchlorate as the electrolyte (Fig. 2). The HOMO/LUMO levels of PTATffBT, PTATBT-8 and PTAT2BT-8 were estimated to be $-5.48 /-3.16 \mathrm{eV}$, $-5.46 /-3.42 \mathrm{eV}$ and $-5.31 /-3.47 \mathrm{eV}$, respectively. The shallower HOMO level of PTAT2BT-8 relative to that of PTATBT-8 occurs as a result of increased intramolecular charge transfer

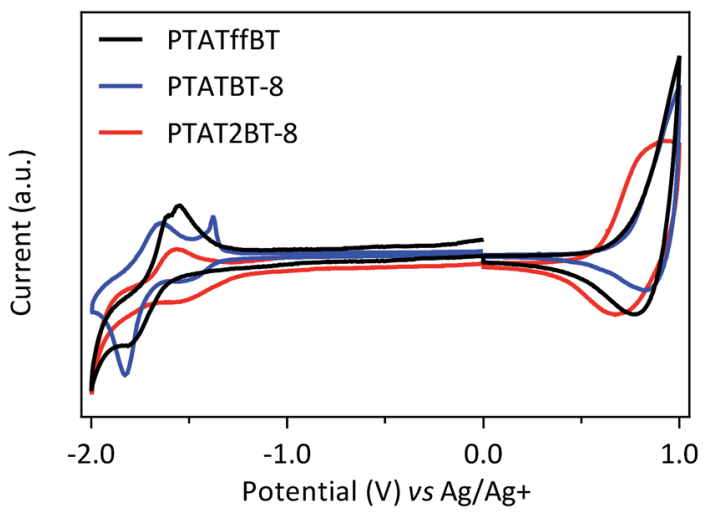

Fig. 2 Cyclic voltammograms of PTATffBT, PTATBT- 8 and PTAT2BT8 on platinum disc electrodes (area $0.031 \mathrm{~cm}^{2}$ ) recorded at a scan rate of $100 \mathrm{mV} \mathrm{s} \mathrm{s}^{-1}$ in acetonitrile/tetrabutylammonium perchlorate $\left(0.1 \mathrm{~mol} \mathrm{dm}^{-3}\right)$. 
along the polymer backbone. Such effects are a consequence of incorporating bithiophene spacer-units into the polymer backbone. However, the LUMO level of PTAT2BT-8 is at a similar energy level to that of PTATBT-8.

PTATffBT has the deepest HOMO level of all polymers synthesised within this report; a consequence of substituting octyloxy groups on the benzothiadiazole-moiety for fluorine. This result is consistent with previous literature that shows that fluorination of acceptor moieties yields deeper HOMO levels. ${ }^{35-38}$ However, the LUMO level of PTATffBT is significantly shallower relative to both PTATBT-8 and PTAT2BT-8. This is not consistent with previous literature findings. We speculate that the low molecular weight of PTATfBT is responsible for this observation. Previous literature has shown that the LUMO level of a polymer decrease more rapidly relative to the HOMO level as the molecular weight increases. ${ }^{39}$ This is attributed to molecular orbital hybridisation of each monomer resulting in localisation of the LUMO level on the acceptor moiety as the $M_{\mathrm{w}}$ of the polymer increases. ${ }^{39}$ We speculate that the low $M_{\mathrm{w}}$ of PTATffBT results in the polymer displaying poor charge transport properties owing to a higher concentration of polymer chain ends and decreased packing density.

PPATBT-8 and PPAT2BT-8 synthesised by Iraqi et al. had HOMO/LUMO levels of $-5.48 /-3.14 \mathrm{eV}$ and $-5.35 /-3.11 \mathrm{eV}$, respectively. ${ }^{33}$ Clearly, the electronic properties of the resulting polymer are changed significantly when the substituents attached at the 9,10-positions of anthracene are modified. The TIPS group is fully conjugated to the anthracene $\pi$-system (resonance effect) and the sp hybridised acetylene carbons are more electron withdrawing than the $\mathrm{sp}^{2}$ hybridised orbitals carbons to which they are attached (inductive effect). Thus, polymers that incorporate TIPS groups induce efficient intramolecular charge separation resulting in a notable decrease in the LUMO level.

\section{Thermal properties}

The thermal properties of all conjugated polymers were investigated using thermogravimetric analysis (TGA). The resulting thermograms of the polymers are plotted in Fig. 3. All polymers possess good thermal stability with degradation temperatures $(5 \%$ weight loss) in excess of $300{ }^{\circ} \mathrm{C}$; a desirable property for the fabrication of organic photovoltaic devices. PTATffBT, PTATBT-8

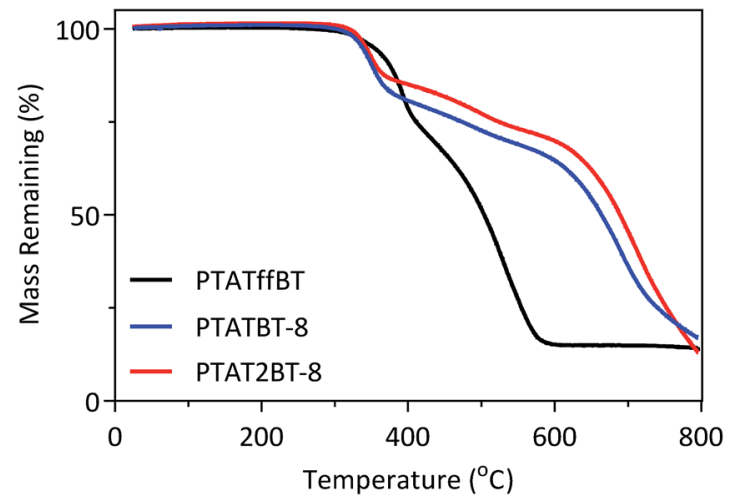

Fig. 3 TGA plots of PTATffBT, PTATBT- 8 and PTAT2BT- 8 with a heating rate of $10{ }^{\circ} \mathrm{C} \mathrm{min}{ }^{-1}$ under an inert atmosphere of nitrogen. and PTAT2BT-8 display degradation temperatures of 352, 334 and $341{ }^{\circ} \mathrm{C}$, respectively. We speculate that the degradation temperatures of PTATBT-8 and PTAT2BT-8 are lower than that of PTATffBT as a result of fluorine substitution. ${ }^{35,40,41}$ It is speculated the octyloxy substituents attached to the 5,6-positions of benzothiadiazole in PTATBT-8 and PTAT2BT-8 are more thermally labile relative to fluorine.

\section{Powder X-ray diffraction studies}

Powder X-ray diffraction (XRD) studies were conducted on the three polymers (Fig. 4). The XRD patterns PTATBT-8 and PTAT2BT-8 display broad diffraction peaks at the angle of $c a$. $22^{\circ}$ and is associated with $\pi-\pi$ stacking. This X-ray diffraction pattern is consistent with many other amorphous donoracceptor conjugated copolymers, for example PCDTBT. ${ }^{\mathbf{4 2}}$

The XRD pattern of PTATffBT displays multiple diffraction peaks ranging from $5.27^{\circ}$ to $25.7^{\circ}$. Previous literature has shown that the sharp intense peak at $5.27^{\circ}$ corresponds to the distance between polymer main chains, where the solubilising alkyl chains organise in an interdigitated manner. ${ }^{43,44}$ The peak at the wide angle of $25.7^{\circ}$ corresponds to a $\pi-\pi$ stacking distance of $3.7 \AA$. The smaller $\pi-\pi$ stacking peak exhibited by PTATffBT, relative to PTATBT-8 and PTAT2BT-8, can be attributed to the different substituents attached to the benzothiadiazole moiety with octyloxy substituents being larger and more sterically demanding than fluorine. The presence of sharp peaks in both the wide-angle and small-angle region suggests that PTATffBT adopts a more crystalline (possibly microcrystalline or semicrystalline) arrangement in solid state as a result of self-organisation of polymer chains forming more ordered domains in the solid state. This will reduce the solubility of PTATffBT in organic solvents, as well as limit its miscibility with the electron acceptor $\mathrm{PC}_{70} \mathrm{BM}$. Compared with that of PTATfBT, the miscibility of PC $_{70} \mathrm{BM}$ with amorphous PTATBT-8 and PTAT2BT-8 is superior, and therefore enables moderate power conversion efficiencies.

\section{Photovoltaic properties}

Photovoltaic measurements were made on a series of glass/ITO/ PEDOT:PSS/polymer : $\mathrm{PC}_{70} \mathrm{BM} / \mathrm{Ca} / \mathrm{Al}$ devices using blends of polymers : $\mathrm{PC}_{70} \mathrm{BM}$ in weight ratios from $1: 1$ to $1: 4$.

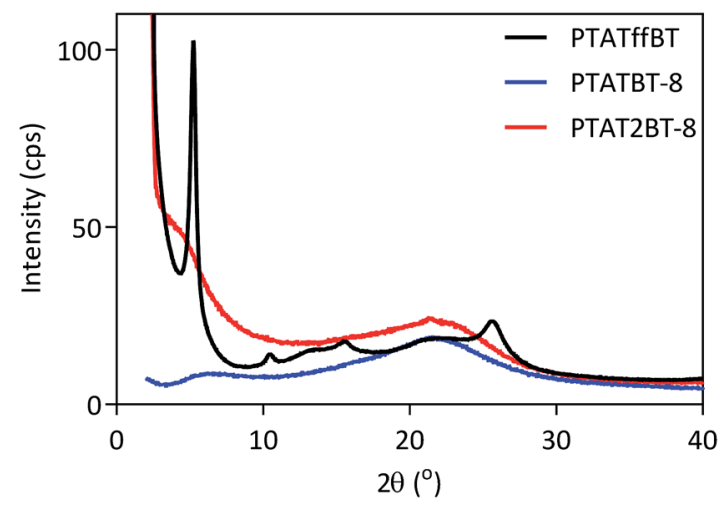

Fig. 4 Powder XRD patterns of PTATffBT, PTATBT-8 and PTAT2BT-8. 
A detailed device-fabrication process is described in the Experimental section. As mentioned previously, the limited solubility of PTATffBT meant that photovoltaic devices could not be fabricated using this polymer. Photovoltaic measurements revealed that devices with the active layer cast from $1: 3$ polymer : $\mathrm{PC}_{70} \mathrm{BM}$ (w/w ratio) had optimum performance. The influence of casting solvent and additives were also investigated (see Table 2). A chlorobenzene casting solvent yielded the best results for PTATBT-8 whilst chloroform was found to be the best solvent for PTAT2BT-8. The addition of 3.0\% diiodooctane (DIO) as an additive did not improve the photovoltaic properties of the polymer but had a detrimental effect on the photovoltaic performance. The $J-V$ characteristic curves for the best performing devices are shown in Fig. 5 a.

Both PTATBT-8 and PTAT2BT-8 exhibit modest performances with PCEs of 2.36 and $3.15 \%$, respectively. Optimised photovoltaic devices fabricated from PTATBT-8 demonstrated an open-circuit voltage $\left(V_{\text {oc }}\right)$ of $0.90 \mathrm{~V}$, a short-circuit current $\left(J_{\mathrm{sc}}\right)$ of $-6.88 \mathrm{~mA} \mathrm{~cm}^{-2}$ and a fill-factor (FF) of $37.8 \%$. In contrast, PTAT2BT-8 displayed a $V_{\mathrm{oc}}$ of $0.74 \mathrm{~V}$, a $J_{\mathrm{sc}}$ of $-8.37 \mathrm{~mA} \mathrm{~cm}{ }^{-2}$ and a $\mathrm{FF}$ of $50.0 \%$. The higher $J_{\mathrm{sc}}$ and $\mathrm{FF}$ of PTAT2BT-8, relative to PTATBT-8, presumably arise as a result of improved packing of polymer chains in polymer : $\mathrm{PC}_{70} \mathrm{BM}$ blends as a result of improving charge mobility and thus extraction of photo-generated charge carriers. It is well documented that the $V_{\text {oc }}$ of photovoltaic devices is closely related to the energy difference between the HOMO of the donor and the LUMO level of the acceptor. ${ }^{45}$ The lower HOMO level of PTAT2BT-8, relative to PTATBT-8 is thus translated into a higher $V_{\text {oc }}$ value. External quantum efficiencies (EQE) for corresponding devices were measured (Fig. 5b). PTAT2BT-8 demonstrated higher EQEs in excess of $45 \%$ between a wider range of wavelengths (380-576 nm) with a peak value of $52 \%$ at $384 \mathrm{~nm}$. In contrast, PTATBT-8 demonstrated EQEs in excess of $45 \%$ between a shorter range of wavelengths (380-388 nm) with a peak value of $46 \%$ at 380 $\mathrm{nm}$. The higher EQE corresponds to improved charge carrier separation and transportation properties, which is consistent with the higher $J_{\mathrm{sc}}$ values recorded for photovoltaic devices fabricated from PTAT2BT-8.

Hole-only devices were fabricated using the structure glass/ ITO/PEDOT:PSS/polymer : $\mathrm{PC}_{70} \mathrm{BM} / \mathrm{Au}$. The dark $J-V$ curves of hole-only devices are presented in Fig. 6 . Following the space charge limited current (SCLC) theory, the hole mobilities of the
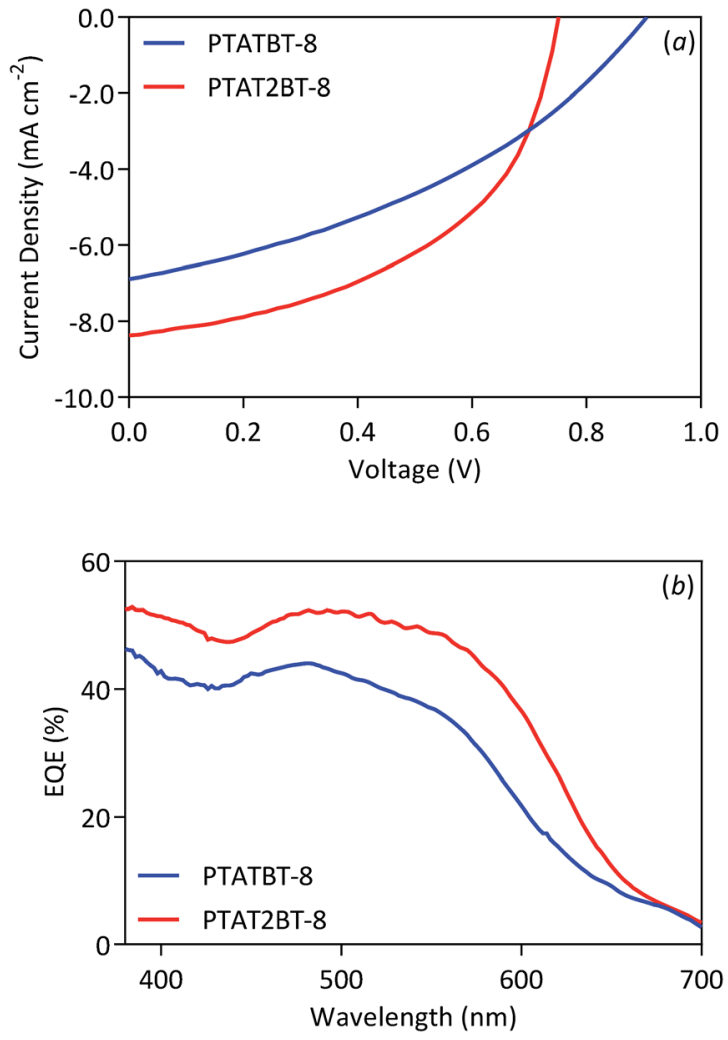

Fig. 5 (a) J-V characteristic curves of photovoltaic devices fabricated from PTATBT-8 and PTAT2BT-8; and (b) external quantum efficiency (EQE) spectra of corresponding devices measured using a monochromatic light source.

two polymer : $\mathrm{PC}_{70} \mathrm{BM}$ films was calculated. ${ }^{46}$ The hole mobility of PTAT2BT-8 : $\mathrm{PC}_{70} \mathrm{BM}$ blends $\left(9.7 \times 10^{-5} \mathrm{~cm}^{2} \mathrm{~V}^{-1} \mathrm{~s}^{-1}\right)$ is higher than PTATBT-8 : $\mathrm{PC}_{70} \mathrm{BM}$ blends $\left(1.6 \times 10^{-5} \mathrm{~cm}^{2} \mathrm{~V}^{-1}\right.$ $\mathrm{s}^{-1}$ ). PTAT2BT-8 displays a higher hole mobility relative to PTATBT-8 despite it possessing a lower molecular weight. We speculate this is a consequence of the incorporation of additional thiophene spacer units in PTAT2BT-8. These promote planarity of the polymer backbone which facilitates charge transportation. Taking both the EQE and hole mobility characterisation into consideration, the improved photovoltaic performance of PTAT2BT-8 : $\mathrm{PC}_{70} \mathrm{BM}$ based devices can be attributed to improved charge carrier separation and subsequent charge extraction.

Table 2 Performance of glass/ITO/PEDOT:PSS/polymer: $\mathrm{PC}_{70} \mathrm{BM} / \mathrm{Ca} / \mathrm{Al} \mathrm{BHJ}$ polymer solar cells under a simulated photovoltaic light with $1000 \mathrm{Wm}^{-2}$ illumination (AM 1.5). PCE values given represent the highest and average values obtained

\begin{tabular}{|c|c|c|c|c|c|c|c|}
\hline Polymer & Polymer : $\mathrm{PC}_{70} \mathrm{BM}^{a}(\mathrm{w} / \mathrm{w})$ & Solvent & $J_{\mathrm{sc}}\left(\mathrm{mA} \mathrm{cm}^{-2}\right)$ & $V_{\mathrm{oc}}(\mathrm{V})$ & FF & PCE (\%) & Thickness(nm) \\
\hline \multirow[t]{2}{*}{ PTATBT-8 } & $1: 3$ & $\mathrm{CF}^{b}$ & -6.66 & 0.88 & 37.5 & $2.20(2.11 \pm 0.10)$ & 70 \\
\hline & $1: 3$ & $\mathrm{CB}^{c}$ & -6.88 & 0.90 & 37.8 & $2.36(2.28 \pm 0.07)$ & 70 \\
\hline \multirow[t]{3}{*}{ PTAT2BT-8 } & $1: 3$ & $\mathrm{CF}^{b}$ & -8.37 & 0.74 & 50.0 & $3.15(2.99 \pm 0.11)$ & 75 \\
\hline & $1: 3$ & $\mathrm{CB}^{c}$ & -8.30 & 0.78 & 41.8 & $2.72(2.56 \pm 0.10)$ & 85 \\
\hline & $1: 3$ & $\mathrm{CB}+\mathrm{DIO}^{d}$ & -4.27 & 0.78 & 65.3 & $2.19(2.08 \pm 0.08)$ & 85 \\
\hline
\end{tabular}

${ }^{a}$ Polymer : $\mathrm{PC}_{70} \mathrm{BM}$ weight ratio. ${ }^{b} \mathrm{CF}=$ chloroform. ${ }^{c} \mathrm{CB}=$ chlorobenzene. ${ }^{d} \mathrm{CB}+\mathrm{DIO}=$ chlorobenzene + diiodooctane $(3 \%$ additive $)$. 


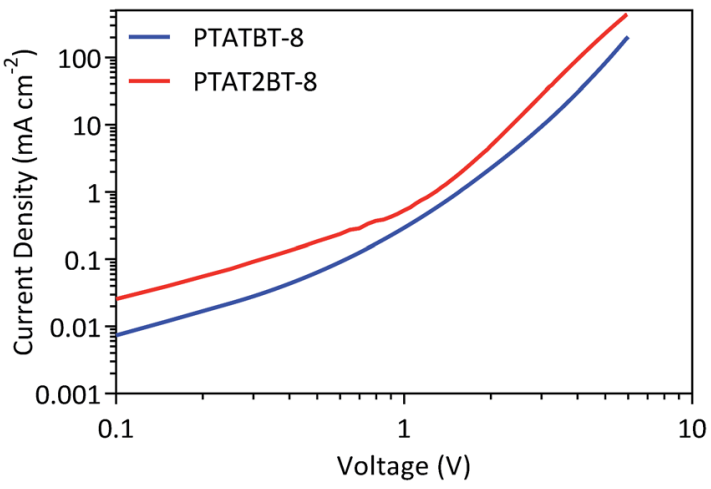

Fig. 6 Dark J-V curves of hole only devices fabricated from PTATBT-8 and PTAT2BT-8.

PPATBT-8 and PPAT2BT-8 synthesised by Iraqi et al. displayed PCEs of 3.92 and $4.17 \%$, respectively. ${ }^{33}$ These are higher than the TIPS-functionalised polymers synthesised. This occurs as a result of higher $J_{\mathrm{sc}}$ and $\mathrm{FF}$ values for PPATBT-8 and PPAT2BT-8 to their comparable TIPS-functionalised analogues. Surprisingly, the smaller optical and electrochemical band-gaps of PTATBT-8 and PTAT2BT-8 did not translate into larger $J_{\mathrm{sc}}$ values.

\section{Atomic force microscopy (AFM) images}

Atomic force microscopy (AFM) in tapping mode was used to image the surface morphologies of PTATBT-8 : $\mathrm{PC}_{70} \mathrm{BM}(1: 3)$ and PTAT2BT-8 : $\mathrm{PC}_{70} \mathrm{BM}(1: 3)$ blend films spin-coated from chlorobenzene and chloroform solutions respectively, as shown in Fig. 7. It should be noted that there is no significant difference in the surface morphologies of the PTATBT-8 and PTAT2BT-8 based blends. Both exhibit smooth, amorphous looking surfaces with no indication of unfavourable large-scale phase separation. Such morphologies should result in efficient
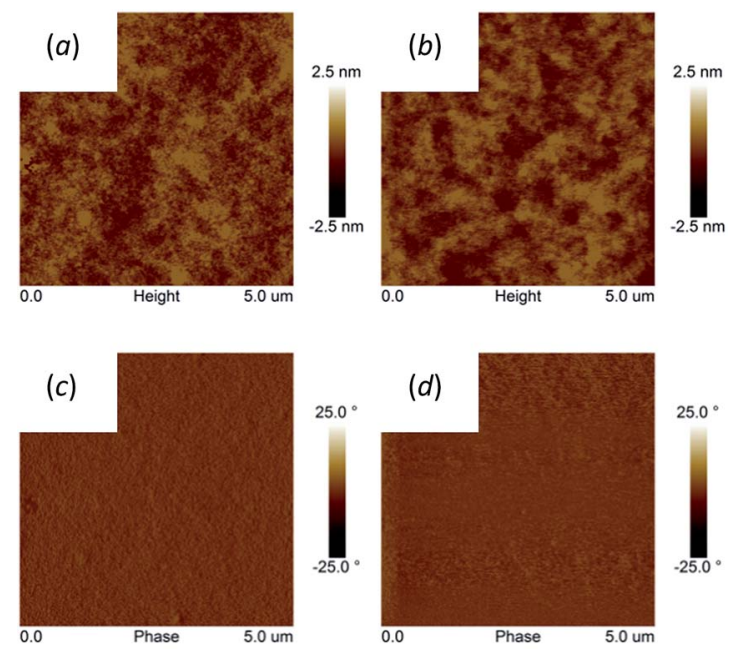

Fig. 7 Tapping-mode atomic force microscopy topography ( $a$ and $b$ ) and phase images ( $c$ and d) of: PTATBT- 8 : PC ${ }_{70} B M(1: 3 \mathrm{w} / \mathrm{w})(\mathrm{a}$ and c); and PTAT2BT- $8:$ PC $_{70}$ BM ( $\left.1: 3 \mathrm{w} / \mathrm{w}\right)(\mathrm{b}$ and d). excitation and photocharge generation. As AFM reveal no significant difference in the surface morphologies of the two types of blend film we tentatively speculate that the improved $J_{\mathrm{sc}}$ associated with devices fabricated from PTAT2BT-8 are a result of difference in improved charge carrier separation and transportation properties, as evidenced by the EQE spectra. This is also reflected by the improved $\mathrm{FF}$ associated with devices fabricated from PTAT2BT-8; a property that results from improved charge-carrier mobility.

\section{Conclusions}

Three triisopropylsilylacetylene-functionalised anthracene (TIPSAnt) based polymers were synthesised by copolymerising TIPSAnt with either dithienyl-5,6-difluoro-benzo[c]-[1,2,5] thiadiazole, dithienyl-benzo[c]-[1,2,5]thiadiazole or dibithiophenyl-benzo[c]-[1,2,5]thiadiazole to yield PTATffBT, PTATBT-8 and PTAT2BT-8, respectively. Whilst chemical characterisation of PTATffBT was possible, the limited solubility of the conjugated polymer in common organic solvents at elevated temperatures meant that fabrication of $\mathrm{BHJ}$ photovoltaic devices via solution processing was not possible. Both PTATBT8 and PTAT2BT-8 displayed excellent solubility in common organic solvents; a consequence of the incorporation of octyloxy-chains onto the 5,6-positions of the benzothiadiazole acceptor-moiety. UV-visible spectroscopy revealed that PTAT2BT-8 had the lowest optical band gap of all polymers synthesised with a value of $1.81 \mathrm{eV}$. We find that PTATffBT had the deepest HOMO level $(-5.48 \mathrm{eV})$; a consequence of utilising a fluorinated-benzothiadiazole acceptor monomer. PTATBT-8 and PTAT2BT-8 had HOMO levels of -5.46 and $-5.31 \mathrm{eV}$. The addition of an additional thiophene spacer unit in PTAT2BT-8 increases intramolecular charge transfer along the polymer backbone resulting in a shallower HOMO level relative to PTATBT-8. BHJ photovoltaic devices fabricated from PTATBT8 : PC $_{70} \mathrm{BM}$ and PTAT2BT-8 : $\mathrm{PC}_{70} \mathrm{BM}$ had efficiencies of 2.36 and $3.15 \%$, respectively. The improved PCE values of PTAT2BT-8 occur primarily as a result of increased $J_{\mathrm{sc}}$ and FF. Taking both the EQE and hole mobility characterisation into consideration the improved photovoltaic performance of PTAT2BT-8 : $\mathrm{PC}_{70} \mathrm{BM}$ based devices can be attribute to improved charge carrier separation and charge transportation.

\section{Experimental section}

\section{Materials}

4.7-Bis(5-bromothiophen-2-yl)-5,6-difluorobenzo[c][1,2,5]thiadiazole (M2), ${ }^{47,48}$ 4,7-bis-(5-bromo-thiophen-2-yl)-5,6-bis-octyloxybenzo[ $[c][1,2,5]$ thiadiazole (M3) ${ }^{49}$ and 4,7-bis-( $5^{\prime}$-bromo- $\left[2,2^{\prime}\right]$ bithiophenyl-5-yl)-5,6-bis-octyloxy-benzo-[1,2,5]thiadiazole $(\mathbf{M 4})^{50}$ were prepared according to previous established literature procedures. $\mathrm{PC}_{70} \mathrm{BM}$ (95\%) was purchased from Ossila Ltd. All chemicals and solvents, with the exception of those stated below, were of reagent grade quality, purchased commercially and used without further purification unless otherwise stated. Toluene was dried and distilled over sodium under an inert argon atmosphere. Acetonitrile (high performance liquid 
chromatography (HPLC) grade) was dried and distilled over phosphorous pentoxide under an inert argon atmosphere, then stored over molecular sieves, 3 A.

\section{Measurements}

${ }^{1} \mathrm{H}$ and ${ }^{13} \mathrm{C}$ nuclear magnetic resonance (NMR) spectra were recorded on either Bruker AV 250 (250 MHz), Bruker AV 400 (400 $\mathrm{MHz}$ ) or Bruker Avance III HD 500 (500 MHz) spectrometers at room temperature, using chloroform-d $\left(\mathrm{CDCl}_{3}\right)$ or at $100{ }^{\circ} \mathrm{C}$ using 1,2-dideutrotetrachloroethane as the solvent. NMR spectra were recorded in parts per million ( $\mathrm{ppm}$ ) relative to tetramethylsilane $\left(\delta_{\mathrm{H}} 0.00\right)$. Coupling constants are given in hertz $(\mathrm{Hz})$. Carbon, nitrogen and sulphur elemental analysis was performed on a Perkin Elmer 2400 series $11 \mathrm{CHNS} / \mathrm{O}$ analyser. Analysis of halides was undertaken using the Schöniger flask combustion method. GPC analysis was conducted on polymer solutions in 1,2,4-trichlorobenzene at $140{ }^{\circ} \mathrm{C}$. Polymer samples were spiked with toluene as a reference. GPC curves were obtained using a Viscotek GPC $_{\max }$ VE 2001 GPC solvent/ sample module and a Waters 410 Differential Refractometer, which was calibrated using a series of narrow polystyrene standards (Polymer Laboratories). TGA traces were obtained using a Perkin Elmer TGA-1 Thermogravimetric Analyser at a scan rate of $10^{\circ} \mathrm{C} \mathrm{min}^{-1}$ under an inert nitrogen atmosphere. Powder XRD samples were recorded on a Bruker D8 Avance diffractometer with a CuK $\alpha$ radiation source $(1.5418 \AA$, rated as $1.6 \mathrm{~kW})$. The scanning angle was conducted over the range $2-40^{\circ}$. UV-visible absorption spectra were recorded at ambient temperature using a Hitachi U-2010 Double Beam UV/Visible Spectrophotometer. Polymer solutions were made using chloroform (spectrophotometric grade) and measured using quartz cuvettes (path length $=1 \times 10^{-2} \mathrm{~m}$ ). Thin films used for absorption spectra were prepared by drop casting solutions onto quartz plates using $1 \mathrm{mg} \mathrm{cm}^{-3}$ polymer solutions that were prepared using chloroform (HPLC grade). Cyclic voltammograms were recorded using a Princeton Applied Research Model 263A Potentiostat/Galvanostat. A three electrode system was employed comprising a Pt disc (area $=3.14 \times 10^{-2} \mathrm{~cm}^{2}$ ), platinum wire and $\mathrm{Ag} / \mathrm{Ag}^{+}$as the working electrode, counter electrode and reference electrode, respectively, in a tetrabutylammonium perchlorate acetonitrile solution $\left(0.1 \mathrm{~mol} \mathrm{dm}^{-3}\right)$. Measurements were conducted on polymer films that were prepared by drop casting $1.0 \mathrm{~mm}^{3}$ of polymer solution $\left(1 \mathrm{mg} \mathrm{cm} \mathrm{cm}^{-2}\right.$ in chloroform (HPLC grade)). In accordance with IUPAC's recommendations, ferrocene was employed as a reference redox system. ${ }^{51}$

\section{Fabrication and testing of BHJ polymer solar cells}

The polymers and $\mathrm{PC}_{70} \mathrm{BM}$ were dissolved separately in either $\mathrm{CF}, \mathrm{CB}$ or $\mathrm{CB}$ with $3 \% \mathrm{DIO}$, and were then put on a hot plate held at $70{ }^{\circ} \mathrm{C}$ overnight with stirring to allow dissolution. The solutions were then mixed at different polymer : fullerene blend ratios before spin casting. Photovoltaic devices were fabricated onto pre-patterned ITO glass substrates ( $20 \mathrm{ohms}$ per square) that were supplied by Ossila Limited. The ITO/glass substrates were first cleaned by sonication in dilute $\mathrm{NaOH}$ followed by IPA. A $30 \mathrm{~nm}$ thick PEDOT:PSS layer was spin-coated onto the ITO/ glass substrates. These were then transferred to a hot-plate held at $120{ }^{\circ} \mathrm{C}$ for 10 minutes before being transferred to a nitrogen glove-box. All active layers were spin cast onto the glass/ITO/PEDOT:PSS substrate. The devices were then transferred into a thermal evaporator for deposition of a cathode $(5 \mathrm{~nm}$ of calcium followed by a $100 \mathrm{~nm}$ of aluminium evaporated at a base pressure of $\sim 10^{-7}$ mbar). The cathode was deposited through a shadow-mask producing a series of independent pixels. Devices were encapsulated using a glass slide and epoxy glue before testing. PCEs were determined using a Newport 92251A-1000 AM 1.5 solar simulator. An NREL calibrated silicon cell was used to calibrate the power output to $100 \mathrm{~mW} \mathrm{~cm}{ }^{-2}$ at $25{ }^{\circ} \mathrm{C}$. An aperture mask having an area of $2.06 \mathrm{~mm}^{2}$ was placed over devices to define the test area. At least two devices were prepared for each sample to give 12 pixels. Each reporting an independent $J-V$ curve. EQE values were determined over the wavelength range of interest by comparing the photocurrent of the OPV cell to a reference silicon photodiode having a known spectral response.

2,6-Bis-(4,4,5,5-tetramethyl-1,3,2-dioxaborolan-2-yl)-9,10-bis(triisopropylsilylacetylene) anthracene (M1). A single neck round bottom containing 2,6-dibromo-9,10-bis(triisopropylsilylacetylene)anthracene $(3.00 \mathrm{~g}, 4.3 \mathrm{mmol})$, bis(pinacolato)diboron $(3.83 \mathrm{~g}, 15.01 \mathrm{mmol})$, potassium acetate $(2.52 \mathrm{~g}, 24.97$ $\mathrm{mmol})$ and $\mathrm{Pd}(\mathrm{dppf}) \mathrm{Cl}_{2}(0.2 \mathrm{~g}, 0.25 \mathrm{mmol})$ was placed under an argon atmosphere using standard Schlenk line techniques. To this mixture, DMF $\left(50 \mathrm{~cm}^{3}\right)$ was added, degassed and heated at $90{ }^{\circ} \mathrm{C}$ for 48 hours. The reaction mixture was cooled to room temperature and poured into water $\left(50 \mathrm{~cm}^{3}\right)$ and extracted with diethyl ether $\left(3 \times 100 \mathrm{~cm}^{3}\right)$. The organic phases were combined, washed with $\mathrm{H}_{2} \mathrm{O}\left(2 \times 100 \mathrm{~cm}^{3}\right)$ and dried $\left(\mathrm{MgSO}_{4}\right)$. The crude product was purified by dissolving in the minimum amount of hot ether and precipitated in methanol which had been run through a basic column $(1.41 \mathrm{~g}, 1.8 \mathrm{mmol}, 41 \%) .{ }^{1} \mathrm{H}$ NMR $(250$ $\left.\mathrm{MHz}, \mathrm{CDCl}_{3}\right):\left(\delta_{\mathrm{H}} / \mathrm{ppm}\right) 9.30(\mathrm{~s}, 2 \mathrm{H}), 8.62(\mathrm{~d}, J=8.48 \mathrm{~Hz}, 2 \mathrm{H})$, $7.94(\mathrm{dd}, J=0.98 \mathrm{~Hz}$ and $J=8.48 \mathrm{~Hz}, 2 \mathrm{H}), 1.41(\mathrm{~s}, 24 \mathrm{H}), 1.32(\mathrm{~m}$, $42 \mathrm{H}) .{ }^{13} \mathrm{C}$ NMR $\left(250 \mathrm{MHz}, \mathrm{CDCl}_{3}\right) \partial(\mathrm{ppm}): 136.42,133.44$, $132.37,130.61,126.91,105.22,103.33,83.93,25.00,18.94$, 11.58. $[\mathrm{M}]^{+}$calculated for $\mathrm{C}_{48} \mathrm{H}_{72} \mathrm{~B}_{2} \mathrm{O}_{4} \mathrm{Si}_{2}, 790.515529$; found, 790.513046. Elemental analysis (\%) calculated for $\mathrm{C}_{48} \mathrm{H}_{72} \mathrm{~B}_{2} \mathrm{O}_{4} \mathrm{Si}_{2}$ : C, 72.90; H, 9.18. Found: C, 73.22; H, 7.72.

Poly[9,10-bis(triisopropylsilylacetylene)-anthracene-2,6-diylalt-(4,7-dithiophen-2-yl)-5,6-difluorobenzo $[c][1,2,5]$ thiadiazole5-5-diyl] (PTATffBT). 4.7-Bis(5-bromothiophen-2-yl)-5,6-difluorobenzo[c] $][1,2,5]$ thiadiazole $(0.181 \mathrm{~g}, 0.367 \mathrm{mmol})$ and 2,6-bis(4,4,5,5-tetramethyl-1,3,2-dioxaborolan-2-yl)-9,10-bis(triisopropylsilylacetylene) anthracene $(0.290 \mathrm{~g}, 0.367 \mathrm{mmol})$ were added to a flask and placed under an inert argon atmosphere using standard Schlenk line techniques. Dry toluene $\left(9 \mathrm{~cm}^{3}\right)$ and tetraethyl ammonium hydroxide $\left(20 \% \mathrm{wt}, 2 \mathrm{~cm}^{3}\right.$, degassed) were added and the reaction was degassed again. $\operatorname{Pd}(\mathrm{OAc})_{2}(6.5 \mathrm{mg}$, $28.9 \mu \mathrm{mol})$ and tri $(o$-tolyl)phosphine $(17.3 \mathrm{mg}, 56.8 \mu \mathrm{mol})$ was added and the reaction mixture was degassed again. The mixture was heated to $90{ }^{\circ} \mathrm{C}$ for 30 minutes. Upon completion, the mixture was cooled to room temperature and bromobenzene $\left(0.1 \mathrm{~cm}^{3}, 0.94 \mathrm{mmol}\right)$ was added. The mixture was degassed and heated at $90{ }^{\circ} \mathrm{C}$ for 1 hour. Upon completion, the reaction 
mixture was cooled to room temperature and phenyl boronic acid (150 mg, $1.23 \mathrm{mmol}$ ) was added. The mixture was degassed and heated at $90{ }^{\circ} \mathrm{C}$ for a further hour. The mixture was cooled to room temperature and precipitated into methanol $\left(500 \mathrm{~cm}^{3}\right.$, degassed) and stirred overnight. The resulting mixture was filtered through a membrane filter and the polymer was obtained as a deep purple powder. The polymer was cleaned using Soxhlet extraction with solvents in the following order: methanol, acetone, hexane and toluene. The toluene fraction was concentrated $\left(\sim 50 \mathrm{~cm}^{3}\right)$ and then poured into degassed methanol $\left(500 \mathrm{~cm}^{3}\right)$. The resulting mixture was stirred overnight and the solid was collected by filtration $(92.4 \mathrm{mg}, 29 \%)$. GPC analysis: $M_{\mathrm{n}}$ $=2100 \mathrm{Da}, M_{\mathrm{w}}=2500 \mathrm{Da}, \mathrm{PDI}=1.19 .{ }^{1} \mathrm{H}-\mathrm{NMR}(500 \mathrm{MHz}$, $\left.\mathrm{C}_{2} \mathrm{D}_{2} \mathrm{Cl}_{4}, 100{ }^{\circ} \mathrm{C}\right)\left(\delta_{\mathrm{H}} / \mathrm{ppm}\right) 8.96(\mathrm{~m}, 1 \mathrm{H}), 8.77-8.52(\mathrm{~m}, 2 \mathrm{H}), 8.38-$ $8.20(\mathrm{~m}, 2 \mathrm{H}), 7.97(\mathrm{~m}, 1 \mathrm{H}), 7.67(\mathrm{~m}, 2 \mathrm{H}), 7.49-7.27(\mathrm{~m}, 2 \mathrm{H}) .{ }^{19} \mathrm{~F}-$ NMR (500 MHz, $\left.\mathrm{C}_{2} \mathrm{D}_{2} \mathrm{Cl}_{4}, 100{ }^{\circ} \mathrm{C}\right)\left(\delta_{\mathrm{F}} / \mathrm{ppm}\right)-127.22,-127.70$. Anal. calcd for $\mathrm{C}_{50} \mathrm{H}_{52} \mathrm{~F}_{2} \mathrm{~N}_{2} \mathrm{~S}_{3} \mathrm{Si}_{2}$ : C, 68.92; $\mathrm{H}$ 6.02; N, 3.22; S, 11.04. Found: C, 67.85; H, 5.93; N, 2.78; S, 9.68.

Poly[9,10-bis(triisopropylsilylacetylene)-anthracene-2,6-diylalt-(5,6-bis(octyloxy)-4,7-di(thiophene-2-yl))benzo[c]thiadiazole5,5-diyl] (PTATBT-8). PTATBT-8 was synthesized according to the polymerisation method outlined for PTATffBT: 4,7-bis (5-bromo-2-thienyl)-5,6-bis(octyloxy)-2,1,3-benzothiadiazole $(0.262 \mathrm{~g}$, $0.367 \mathrm{mmol}$ ) and 2,6-bis-(4,4,5,5-tetramethyl-1,3,2-dioxaborolan2-yl)-9,10-bis(triisopropylsilylacetylene) anthracene $(0.290 \mathrm{~g}$, $0.367 \mathrm{mmol}$ ) were added to a flask and placed under an inert argon atmosphere using standard Schlenk line techniques. Dry toluene $\left(10 \mathrm{~cm}^{3}\right)$ and tetraethyl ammonium hydroxide $(20 \% \mathrm{wt}$, $2.1 \mathrm{~cm}^{3}$, degassed) were added and the reaction was degassed again. $\mathrm{Pd}(\mathrm{OAc})_{2}(6.0 \mathrm{mg}, 26.7 \mu \mathrm{mol})$ and tri(o-tolyl)phosphine (16.3 mg, $53.6 \mu \mathrm{mol})$ was added and the reaction mixture was degassed again. The mixture was heated to $90{ }^{\circ} \mathrm{C}$. The polymerisation was deemed complete after 3 hours. The polymer was obtained as a purple solid (230 mg, 57\%). GPC analysis: $M_{\mathrm{n}}=$ $13600 \mathrm{Da}, M_{\mathrm{w}}=38700 \mathrm{Da}, \mathrm{PDI}=2.84 .{ }^{1} \mathrm{H}-\mathrm{NMR}(500 \mathrm{MHz}$, $\left.\mathrm{C}_{2} \mathrm{D}_{2} \mathrm{Cl}_{4}, 100{ }^{\circ} \mathrm{C}\right)\left(\delta_{\mathrm{H}} / \mathrm{ppm}\right) 8.89(\mathrm{br}, 1 \mathrm{H}), 8.82-8.32(\mathrm{~m}, 4 \mathrm{H}), 7.99$ (br, 1H), 7.67 (br, 2H), 7.49-7.22 (m, 2H), 4.21 (br, 4H), 1.94 (br, $4 \mathrm{H}), 1.55-1.01(\mathrm{~m}, 62 \mathrm{H}), 0.80(\mathrm{br}, 6 \mathrm{H})$. Anal. calcd for $\mathrm{C}_{66}{ }^{-}$ $\mathrm{H}_{86} \mathrm{~N}_{2} \mathrm{O}_{2} \mathrm{~S}_{3} \mathrm{Si}_{2}$ : C, 72.61; H 7.94; N, 2.57; S, 8.81. Found: C, 70.16; $\mathrm{H}, 6.55$; N, 3.35; S, 10.35 .

Poly(9,10-bis(triisopropylsilylacetylene)-anthracene-2,6-diylalt-(5,6-bis(octyloxy)-4,7-di(2,2'-bithiophen-5-yl)benzo[c] $[1,2,5]$ thiadiazole)-5,5-diyl) (PTAT2BT-8). PTAT2BT-8 was synthesized according to the polymerisation method outlined for PTATffBT: 4,7-bis(5'-bromo-2,2'-bithien-5-yl)-5,6-bis(octyloxy)-2,1,3-benzothiadiazole $(0.323 \mathrm{~g}, 0.367 \mathrm{mmol})$ and 2,6-bis-(4,4,5,5-tetramethyl-1,3,2dioxaborolan-2-yl)-9,10-bis(triisopropylsilylacetylene) anthracene $(0.290 \mathrm{~g}, 0.367 \mathrm{mmol})$ were added to a flask and placed under an inert argon atmosphere using standard Schlenk line techniques. Dry toluene $\left(10 \mathrm{~cm}^{3}\right)$ and tetraethyl ammonium hydroxide $(20 \%$ wt, $2.1 \mathrm{~cm}^{3}$, degassed) were added and the reaction was degassed again. $\mathrm{Pd}(\mathrm{OAc})_{2}(6.1 \mathrm{mg}, 27.2 \mu \mathrm{mol})$ and tri(o-tolyl $)$ phosphine (16.1 $\mathrm{mg}, 53.0 \mu \mathrm{mol})$ was added and the reaction mixture was degassed again. The mixture was heated to $90{ }^{\circ} \mathrm{C}$. The polymerisation was deemed complete after 1 hour. The polymer was obtained as a deep purple solid (76.7 mg, 17\%). GPC analysis: $M_{\mathrm{n}}=$ $6600 \mathrm{Da}, M_{\mathrm{w}}=13200 \mathrm{Da}, \mathrm{PDI}=2.00 .{ }^{1} \mathrm{H}-\mathrm{NMR}\left(500 \mathrm{MHz}, \mathrm{C}_{2} \mathrm{D}_{2} \mathrm{Cl}_{4}\right.$, $\left.100{ }^{\circ} \mathrm{C}\right)\left(\delta_{\mathrm{H}} / \mathrm{ppm}\right) 8.87(\mathrm{~s}, 1 \mathrm{H}), 8.62(\mathrm{~d}, 2 \mathrm{H}, J=8.50 \mathrm{~Hz}), 8.44(\mathrm{~m}$, $2 \mathrm{H}), 7.88(\mathrm{~d}, 2 \mathrm{H}, J=8.50 \mathrm{~Hz}), 7.67-6.95(\mathrm{~m}, 9 \mathrm{H}), 4.20(\mathrm{br}, 4 \mathrm{H}), 1.97$ (br, 4H), 1.56-1.09 (m, 62H), $0.86(\mathrm{br}, 6 \mathrm{H})$. Anal. calcd for $\mathrm{C}_{74^{-}}$ $\mathrm{H}_{90} \mathrm{~N}_{2} \mathrm{O}_{2} \mathrm{~S}_{5} \mathrm{Si}_{2}$ : C, 70.67; H 7.22; N, 2.23; S, 12.76. Found: C, 71.01; $\mathrm{H}, 7.01$; N, 2.92; S, 14.98.

\section{Acknowledgements}

We would like to thank EPSRC for financial support of this work via research grants EP/J017361/1 and EP/I028641/1. YZ thanks the University of Sheffield for the award of a scholarship. TW acknowledges financial support from the Recruitment Program of Global Experts and the Natural Science Foundation of China (Grant No. 21504065).

\section{References}

1 G. Dennler, M. C. Scharber and C. J. Brabec, Adv. Mater., 2009, 21, 1323-1338.

2 J. Y. Kim, K. Lee, N. E. Coates, D. Moses, T. Nguyen, M. Dante and A. J. Heeger, Science, 2007, 317, 222-226.

3 G. Yu, J. Gao, J. C. Hummelen, F. Wudl and A. J. Heeger, Science, 1995, 270, 1789-1791.

4 Y. Liu, J. Zhao, Z. Li, C. Mu, W. Ma, H. Hu, K. Jiang, H. Lin, H. Ade and H. Yan, Nat. Commun., 2014, 5, 1-8.

5 M. C. Scharber and N. S. Sariciftci, Prog. Polym. Sci., 2013, 38, 1929-1940.

6 J.-D. Chen, C. Cui, Y.-Q. Li, L. Zhou, Q.-D. Ou, C. Li, Y. Li and J.-X. Tang, Adv. Mater., 2015, 27, 1035-1041.

7 S. Günes, H. Neugebauer and N. S. Sariciftci, Chem. Rev., 2007, 107, 1324-1338.

8 M. M. Wienk, J. M. Kroon, W. J. H. Verhees, J. Knol, J. C. Hummelen, P. A. van Hal and R. A. J. Janssen, Angew. Chem., Int. Ed., 2003, 42, 3371-3375.

9 C. J. Brabec, G. Zerza, G. Cerullo, S. de Silvestri, S. Luzzati, J. C. Hummelen and S. Sariciftci, Chem. Phys. Lett., 2001, 340, 232-236.

10 J. W. Arbogast and C. S. Foote, J. Am. Chem. Soc., 1991, 113, 8886-8889.

11 L. Chen, P. Shen, Z. Zhang and Y. Li, J. Mater. Chem. A, 2015, 3, 12005-12015.

12 D. Mühlbacher, M. Scharber, M. Morana, Z. Zhu, D. Waller, R. Gaudiana and C. Brabec, Adv. Mater., 2006, 18, 2884-2889.

13 R. R. Søndergaard, M. Hösel and F. C. Krebs, J. Polym. Sci., Part B: Polym. Phys., 2013, 51, 16-34.

14 R. Søndergaard, M. Hösel, D. Angmo, T. T. Larsen-Olsen and F. C. Krebs, Mater. Today, 2012, 15, 36.

15 H. Kallmann and M. Pope, J. Chem. Phys., 1959, 30, 585-586. 16 Y. Li, T.-H. Kim, Q. Zhao, E.-K. Kim, S.-H. Han, Y.-H. Kim, J. I. N. Jang and S.-K. Kwon, J. Polym. Sci., Part A: Polym. Chem., 2008, 46, 5115-5122.

17 C. Liu, W. Cai, X. Guan, C. Duan, Q. Xue, L. Ying, F. Huang and Y. Cao, Polym. Chem., 2013, 4, 3949-3958.

18 J. W. Jung and W. H. Jo, Polym. Chem., 2015, 6, 4013-4019.

19 C. Liu, W. Xu, X. Guan, H. Yip, X. Gong, F. Huang and Y. Cao, Macromolecules, 2014, 47, 8585-8593. 
20 D. A. M. Egbe, S. Türk, S. Rathgeber, F. Kühnlenz, R. Jadhav, A. Wild, E. Birckner, G. Adam, A. Pivrikas, V. Cimrova, G. Knör, N. S. Sariciftci and H. Hoppe, Macromolecules, 2010, 43, 1261-1269.

21 D. A. M. Egbe, G. Adam, A. Pivrikas, A. M. Ramil, E. Birckner, V. Cimrova, H. Hoppe and N. S. Sariciftci, J. Mater. Chem., 2010, 20, 9726-9734.

22 J. U. Ju, D. S. Chung, S. O. Kim, S. O. Jung, C. E. Park, Y.-H. Kim and S.-K. Kwon, J. Polym. Sci., Part A: Polym. Chem., 2009, 47, 1609-1616.

23 H. Meng, F. Sun, M. B. Goldfinger, G. D. Jaycox, Z. Li, W. J. Marshall and G. S. Blackman, J. Am. Chem. Soc., 2005, 127, 2406-2407.

24 J. Y. Back, T. K. An, Y. R. Cheon, H. Cha, J. Jang, Y. Kim, Y. Baek, D. S. Chun, S.-K. Kwon, C. E. Park and Y.-H. Kim, ACS Appl. Mater. Interfaces, 2015, 7, 351-358.

25 H.-J. Yun, D. S. Chung, I. Kang, J. W. Park, Y.-H. Kim and S.-K. Kwon, J. Mater. Chem., 2012, 22, 24924-24929.

26 S. Tao, Y. Zhou, C.-S. Lee, S.-T. Lee, D. Huang and X. Zhang, J. Phys. Chem. C, 2008, 112, 14603-14606.

27 J. Huang, J. Su and H. Tian, J. Mater. Chem., 2012, 22, 1097710989.

28 H. Kim, H. Lee, D. Seo, Y. Jeong, K. Cho, J. Lee and Y. Lee, Chem. Mater., 2015, 27, 3102-3107.

29 S. Liu, X. Bao, W. Li, K. Wu, G. Xie, R. Yang and C. Yang, Macromolecules, 2015, 48, 2948-2957.

30 L. Huo and J. Hou, Polym. Chem., 2011, 2, 2453-2461.

31 W. Chen, Z. Du, L. Han, M. Xiao, W. Shen, T. Wang, Y. Zhou and R. Yang, J. Mater. Chem. A, 2015, 3, 3130-3135.

32 J.-H. Park, D. S. Chung, D. H. Lee, H. Kong, I. H. Jung, M.-J. Park, N. S. Cho, C. E. Park and H.-K. Shim, Chem. Commun., 2010, 46, 1863-1865.

33 M. S. Almeataq, H. Yi, S. Al-Faifi, A. A. B. Alghamdi, A. Iraqi, N. W. Scarratt, T. Wang and D. G. Lidzey, Chem. Commun., 2013, 49, 2252-2254.

34 J. Park, D. S. Chung, J. Park, T. Ahn, H. Kong, Y. K. Jung, J. Lee, M. H. Yi, C. E. Park, S.-K. Kwon and H. Shim, Org. Lett., 2007, 9, 2573-2576.
35 L. Cartwright, A. Iraqi, Y. Zhang, T. Wang and D. G. Lidzey, RSC Adv., 2015, 5, 46386-46394.

36 T. Umeyama, Y. Watanabe, E. Douvogianni and H. Imahori, J. Phys. Chem. C, 2013, 117, 21148-21157.

37 Y. Zhang, S.-C. Chien, K.-S. Chen, H.-L. Yip, Y. Sun, J. A. Davies, F.-C. Chen and A. K. Y. Jen, Chem. Commun., 2011, 47, 11026-11028.

38 D. Dang, W. Chen, R. Yang, W. Zhu, W. Mammo and E. Wang, Chem. Commun., 2013, 49, 9335-9337.

39 B. Kim, X. Ma, C. Chen, Y. Ie, E. W. Coir, H. Hashemi, Y. Aso, P. F. Green, J. Kieffer and J. Kim, Adv. Funct. Mater., 2013, 23, 439-445.

40 Z. Li, J. Lu, S.-C. Tse, J. Zhou, X. Du, Y. Tao and J. Ding, J. Mater. Chem., 2011, 21, 3226-3233.

41 A. Iyer, J. Bjorgaard, T. Anderson and M. E. Köse, Macromolecules, 2012, 45, 6380-6389.

42 T. Wang, A. J. Pearson, A. D. F. Dunbar, P. A. Staniec, D. C. Watters, H. Yi, A. J. Ryan, R. A. L. Jones, A. Iraqi and D. G. Lidzey, Adv. Funct. Mater., 2012, 22, 1399-1408.

43 S. H. Chen, A. C. Su and S. A. Chen, J. Phys. Chem. B, 2005, 109, 10067-10072.

44 M. Grell, D. D. C. Bradley, G. Ungar, J. Hill and K. S. Whitehead, Macromolecules, 1999, 32, 5810-5817.

45 M. C. Scharber, D. Mühlbacher, M. Koppe, P. Denk, C. Waldauf, A. J. Heeger and C. J. Brabec, Adv. Mater., 2006, 18, 789-794.

46 Y. Liang, Z. Xu, J. Xia, S. Tsai, Y. Wu, G. Li, C. Ray and L. Yu, Adv. Energy Mater., 2010, 22, 135-138.

47 N. Cho, K. Song, J. K. Lee and J. Ko, Chem.-Eur. J., 2012, 18, 11433-11439.

48 H. Zhou, L. Yang, A. C. Stuart, S. C. Price, S. Liu and W. You, Angew. Chem., Int. Ed., 2011, 50, 2995-2998.

49 R. Qin, W. Li, C. Li, C. Du, C. Veit, H.-F. Schleiermacher, M. Andersson, Z. Bo, Z. Liu, O. Inganäs, U. Wuerfel and F. Zhang, J. Am. Chem. Soc., 2009, 131, 14612-14613.

50 H. Yi, S. Al-Faifi, A. Iraqi, D. C. Watters, J. Kingsley and D. G. Lidzey, J. Mater. Chem., 2011, 21, 13649-13656. 51 G. Gritzner, Pure Appl. Chem., 1990, 62, 1839-1858. 